\title{
Non-atopic Rhinitis at Age 6 is Associated with Subsequent Development of Asthma
}

\author{
Tara F Carr, MD, Debra A Stern, MS, Marilyn Halonen, PhD, Anne L Wright, PhD, and \\ Fernando D Martinez, MD
}

Asthma and Airway Disease Research Center, University of Arizona - Tucson, AZ/US

\section{Abstract \\ Background-It has been postulated that the association between allergic rhinitis and asthma is attributable to the progressive clinical expression of respiratory inflammation during childhood. The role of non-allergic rhinitis in early life in relation to subsequent asthma has not been extensively explored.}

Objective-We sought to determine whether rhinitis in early life was associated with risk of asthma development into adulthood, and whether this relationship is independent of allergic sensitization.

\begin{abstract}
Methods-Participants were identified from the Tucson Children's Respiratory study, a nonselected birth cohort. Allergy skin prick testing was performed at age 6 years using house dust mix, Bermuda, mesquite, olive, mulberry, careless weed, and Alternaria aeroallergens. Atopy was defined as $\geq 1$ positive tests. Physician diagnosed active asthma from ages 6-32 and physician diagnosed rhinitis at age 6 were determined by questionnaire. Participants with asthma or active wheezing at age 6 were excluded from analyses. Risk estimates were obtained with Cox regression.
\end{abstract}

\begin{abstract}
Results-There were 521 participants who met inclusion criteria. The hazard ratio for subsequently acquiring a diagnosis of asthma between the ages of 8 and 32 for those with nonatopic rhinitis was 2.1 (95\% CI: 1.2, 3.4, p=0.005), compared with the non-atopic no rhinitis group, after adjusting for sex, ethnicity, maternal asthma, maternal education and smoking, and history of $4+$ colds per year at age 6 . Among the atopic participants, both the active and no rhinitis groups were more likely to develop and have asthma through age 32 . The relation between non-atopic rhinitis and asthma was independent of total serum IgE levels at age 6.
\end{abstract}

\footnotetext{
Corresponding author: Tara F Carr, MD, 1501 N Campbell Ave, Tucson, AZ 85724-5030, phone 520-626-7514, fax 520-626-1876, tcarr@deptofmed.arizona.edu.

Author Contributions:

TFC, DAS, and FDM contributed to conception, design, and analysis of data. DAS, MH, ALW and FDM contributed to acquisition of data. All authors participated in data interpretation, critical revisions of draft for important intellectual content, and approval of the final version of the manuscript. All authors agree to be accountable for all aspects of the work.

Clinical Implications:

Childhood rhinitis, in the absence of atopy, confers significant risk for asthma development through adulthood. These findings underscore the importance of non-allergic respiratory inflammation in the development of asthma.

Partial data was presented in part at the American Thoracic Society 2015 International Conference, Denver CO.

Conflicts of interest: none
} 
Conclusion and Clinical Relevance-Childhood rhinitis, even in the absence of atopy, confers significant risk for asthma development through adulthood. These findings underscore the importance of non-allergic mechanisms in the development of asthma.

\section{Capsule Summary:}

Using data from the Tucson Children's Respiratory Study, we show that rhinitis at age 6, even in the absence of atopy, confers significant risk for the subsequent development of asthma through adulthood.

\section{Keywords}

asthma; inflammation; non-allergic; non-atopic; rhinitis

\section{Introduction}

The paradigm of the "atopic march" describes the development of asthma as part of an earlylife progression through the spectrum of allergic diseases: atopic dermatitis or food allergy, allergic rhinitis, and atopic asthma $(1,2)$. Allergic rhinitis has indeed been identified as a risk factor for onset of asthma(3), recurrent childhood cough and wheezing $(4,5)$, persistence of asthma(6), and severity of asthma(7). It is postulated that the association between rhinitis and asthma is attributable to the progressive allergen sensitization and clinical expression of respiratory inflammation during childhood $(1,8,9)$. However, aeroallergen exposure in sensitized individuals is insufficient to induce development of asthma, which likely requires a localized epithelial or systemic immune response to drive the airway changes characteristic of asthma $(10,11)$. Indeed, additional non-allergic triggers of respiratory inflammation such as smoke exposure and infectious illness confer additional risk for the development of asthma(12). Notably, viral infection, particularly in the form of wheezing lower respiratory illness in early life, is a risk factor for asthma identified in large longitudinal cohorts(13-17). Studies show that asthma development is further associated with viral lower respiratory infection with antecedent or concurrent aeroallergen sensitivity $(14,18)$.

Non-allergic rhinitis is characterized by nasal inflammation due to non-IgE-mediated triggers, including infection, noxious odors, climate variation, medication, and hormones(19, 20). In pediatric cohorts, the burden of non-allergic rhinitis is estimated at between 4 $12 \%(21-24)$. Non-allergic rhinitis has been associated with concurrent asthma in a pediatric cohort(25). Similarly, in cross-sectional studies of adolescents or adults, non-allergic rhinitis has been associated with asthma diagnosis $(26,27)$ or markers of airway inflammation(28). However, the relationship between non-allergic rhinitis in childhood and incident asthma has not been evaluated longitudinally. We therefore sought to determine whether rhinitis in early life was associated with risk of asthma development into adulthood, and whether this risk was independent of allergic sensitization. We hypothesized that rhinitis at age 6 would be associated with subsequent asthma development among both nonatopic and atopic individuals. 


\section{Methods}

Participants were identified from the Tucson Children's Respiratory Study (TCRS), a nonselected birth cohort enrolled from 1980-1984(29). The enrollment process and study design have been presented previously, including the active physician assessment of lower respiratory illness to age 3(30). Participants of TCRS underwent the first in-depth study visit at age 6 . At this visit, questionnaires about the respiratory health of the child were completed by the child's caregiver which included reports of sinusitis, eczema, and upper respiratory infection frequency. Body mass index was determined at each age from questionnairedetermined height and weight. Blood was collected for subsequent measurement of total serum IgE and eosinophil counts. IgE was measured by Phaedebas radioimmunosorbent test using commercially available kits (Pharmacia Diagnostics, Piscataway, NJ USA) as previously reported(31). Percentage of eosinophils was determined by a differential of 300 white blood cells on peripheral blood (32). Lung function testing was performed at age 6 by measurement of maximal forced expiratory flow at functional residual capacity (VmaxFRC) as in previously published methods(33). Bronchial hyperreactivity was assessed using cold air challenge at age 6 , defined as a drop greater than $41.1 \%$, the $90^{\text {th }}$ percentile for decline for reference children as previously described $(15,34)$. Allergy skin prick testing was performed using a panel of extracts from house dust mix (1:10 w/v), Bermuda grass (1:20 $\mathrm{w} / \mathrm{v})$, mesquite tree $(1: 20 \mathrm{w} / \mathrm{v})$, olive tree $(1: 20 \mathrm{w} / \mathrm{v})$, mulberry tree $(1: 20 \mathrm{w} / \mathrm{v})$, careless weed $(1: 20 \mathrm{w} / \mathrm{v})$, and Alternaria alternata (1:100 w/v) aeroallergens (Hollister-Stier Laboratories, Everett, WA, USA), with saline and histamine controls. A skin test wherein the sum of the longest diameter plus the diameter of the orthogonal was at least $3 \mathrm{~mm}$ was considered positive(35). Atopy was defined as one or more positive skin test.

Rhinitis was determined(5) by an affirmative response at age 6 to the question "Has this child ever had hay fever or any other condition that makes his/her nose stuffy, itchy or runny apart from colds?" Rhinitis was classified as active or inactive based on a response to the question "How old was this child when you last noticed this condition?" Rhinitis was classified as "active" if the condition was still present at the time of the interview, or if symptoms of rhinitis were reported for the previous year.

Physician diagnosed active asthma at age 6 (6.1 years [standard deviation(SD), 0.7 years]) was determined by an affirmative response to the question "Has your child ever had asthma?" and age was recorded for the question "How old was the child when the doctor first said he/she had asthma?" Whether the asthma and wheezing was active was determined by the questions "During the past year, how often has this child had wheezing or whistling?" or "During the past year, how many asthma attacks or episodes did this child have?" with any wheeze or asthma attacks in the past year qualifying as "active". The same questions were used in questionnaires completed by the caregiver through age 16 and by the participant starting at age 18 . The history of transient wheeze was defined by wheezing assessed by a physician, during a lower respiratory illness, by three years of age but not at the age of six (33). Early onset asthma was defined as first diagnosis of active asthma after age 6 but before age 18 . Within this group, early onset remitting asthma had last diagnosis before age 18 and early persistent asthma had at least one diagnosis of active asthma at or 
after age 18. Late onset asthma was defined as first diagnosis of active asthma at or after age 18.

History of eczema at age 6 was determined by response to the question "Has this child ever had eczema (allergic skin reaction)?" History of sinusitis at age 6 was determined by response to the question "Has this child ever had sinus trouble, diagnosed by a doctor?" Frequency of upper respiratory illness was determined by response to the question "On average, how many head colds (common colds) does this child usually have per year?"

Participants of TCRS were followed prospectively through age 32. Allergy skin prick testing was again performed at ages 11,16, 22, and 26. Atopy at these ages was defined as one or more positive skin test to Alternaria, Bermuda grass, careless weed, olive, mesquite and/or mulberry (these allergens were included in the panels at all ages). Participants also completed questionnaires periodically through age 32 (ages [mean, SD; number of respondents] 8 [8.5, 0.7; 456], 11 [10.8, 0.6; 508], 13 [13.4, 0.6; 400], 16 [16.5, 0.6; 423], 18 [18.6, 0.7; 396], 22 [22.0, 0.8; 420], 24 [24.3, 1.1; 353], 26 [26.4, 0.7; 379], 29 [28.8, 1.0; $301], 32$ [31.8, 1.1; 352]), at which physician diagnosed active asthma was reported. Active smoking was determined starting at age 16 from questionnaire data (36). Approximately $79 \%$ of the subjects answered 5 or more of the 10 follow up questionnaires, and $50 \%$ answered 8 or more questionnaires.

Children were categorized into four groups based on whether they had rhinitis and/or atopy at age 6. This study is limited to participants with no active asthma and no active wheeze at age 6. Demographic variables for those included or not included were compared using chisquare or ANOVA. Risk estimates for the association of non-atopic rhinitis and asthma were obtained with Cox proportional hazards model. A positive asthma diagnosis event was defined as the first age with active physician diagnosed asthma, and a negative event was defined as the last available questionnaire data point without diagnosis of asthma. Covariates included in the Cox models were survey age, gender, ethnicity, maternal asthma, maternal education, maternal smoking at enrollment, and history of $4+$ colds per year at age 6 . These covariates were included in the analysis because they were previously shown to be associated with altered risk for asthma. We also included history of $4+$ colds per year in the model as it is often a cause of rhinitis. Interactions were assessed between the main predictor and all relevant covariates. In order to assess the role of total serum IgE on the relation between rhinitis and asthma, we additionally adjusted the Cox models by log base 10transformed total serum $\operatorname{IgE}$ at age 6. Risk estimates that adjusted for time dependent active smoking and body mass index were estimated with generalized estimating equations. Pvalues less than 0.05 were considered significant.

This research was approved by the Institutional Review Board of the University of Arizona, approval No. 7500000005, and informed consent/assent was obtained from/for all subjects.

\section{Results}

We identified 521 participants who had 1) no active asthma or active wheezing during the past year at age 6,2) skin test results, and 3) any questionnaire response about asthma from 
ages 8 to 32 (Supplemental Figure SI). Included participants were more likely to be female, have older parents with more years of education and to be non-Hispanic White, compared to participants excluded for lack of complete data (Supplemental Table SI). Parental history of asthma and smoking were similar for those with complete and incomplete data. We also compared characteristics of individuals included to those excluded for lack of skin prick testing ( $n=241$ ) (Supplemental Table SI). Participants with skin prick testing were more likely to be female, non-Hispanic White, and to have less parental history of asthma compared with those excluded for lack of skin prick testing (Supplemental Table SII).

The demographic and clinical characteristics differ among the four groups of children defined by atopy and rhinitis status (Table I) and in a manner consistent with expectations for children with atopy. Active rhinitis was noted in 198 (38.0\%) participants at age 6, whereas atopy was identified in $173(33.2 \%)$ of participants at that same age. Children in the atopic groups had higher total serum IgE, blood eosinophils, and were more likely to have a diagnosis of eczema, than those in the non-atopic groups. Children with any active rhinitis were more likely to have had a physician diagnosis of sinusitis and recurrent upper respiratory infection (URI), compared to those without rhinitis, and proportions with these conditions were similar for the atopic and non-atopic rhinitis groups. The total serum IgE in the non-atopic rhinitis group was not different than that of the non-atopic, no rhinitis group. History of transient wheezing due to lower respiratory illness before age 3(33) and lung function, measured as VmaxFRC, were not significantly different among the groups. The non-atopic rhinitis group were less likely to report itchy eyes (40\%) compared to the atopic rhinitis group $(55 \%), p=0.039$. However, similar proportions of the non-atopic and atopic rhinitis groups reported using medication for nasal symptoms three or more times during the past year (35\% compared to $36 \%$, respectively, $\mathrm{p}=0.9$ )

Among non-atopic children, those with rhinitis were significantly more likely to develop and have asthma through age 32 compared to those with no rhinitis (Hazard Ratio(HR) 2.1, 95\%CI: 1.2, 3.4, $\mathrm{p}=0.005$ ), in models that include survey age, sex, ethnicity, maternal asthma, maternal education and smoking, and average number of colds per year at age 6 (Table II and Supplemental Table SIII). Among the atopic participants, both the active rhinitis (HR 3.7, 95\%CI: 2.2, 6.1, p<0.001) and no rhinitis groups (HR 1.8, 95\%CI: 1.0, 3.2, $\mathrm{p}=0.035$ ) had increased risk of asthma through age 32 when compared with the non-atopic, no rhinitis group. These relations were independent of the frequency of colds, transient wheeze during lower respiratory illnesses, and eczema at age 6 (Table II). The relation between non-atopic rhinitis and asthma was independent of total serum IgE levels at age 6 when added to the fully adjusted model (HR $1.9,95 \% \mathrm{CI}: 1.0,3.5, \mathrm{p}=0.034$, Table II). No interaction was seen between any rhinitis group and sex, ethnicity, maternal asthma, smoking, or history of 4+ URIs (data not shown).

The Cox hazard analysis for development of asthma after age 6, by atopy and rhinitis group, is presented in Figure I. This model is adjusted for confounders including gender, ethnicity, maternal asthma, maternal education, parental smoking, and history of 4+ URIs per year at age 6. Statistics for all covariates in this model are presented in Supplemental Table SIII. To assess for the potential for confounding of rhinitis and asthma risk by body mass index and smoking, we performed a longitudinal generalized estimating equation adjusting for time- 
dependent body mass index and current smoking at the time of each asthma assessment. We found that addition of these confounding variables to the unadjusted and fully adjusted longitudinal model did not reduce the risk associated with rhinitis for development of asthma (data not shown).

We then compared the likelihood of developing atopy, identified by subsequent skin testing through age 26, for the non-atopic no rhinitis and the non-atopic active rhinitis groups. We found no significant difference in the prevalence of subsequent positive skin test tests at age $11,16,22$ or 26 between these two groups (Table III).

Finally, we described the proportion of participants in each rhinitis and atopy group with early onset and late onset asthma (Figure II). Of the participants who developed asthma $(n=117)$, early onset asthma was identified in $54.5 \%$ (18/33) of the non-atopic no rhinitis group, $63.3 \%$ (19/30) of the non-atopic active rhinitis group, $45 \%$ (9/20) of the atopic no rhinitis group and $88.2 \%$ (30/34) of those with atopy and rhinitis. Among those with early onset asthma $(\mathrm{n}=76)$, persistent asthma was most common in the non-atopic rhinitis $(84.2 \%$ $(16 / 19))$ and atopic no rhinitis $(88.9(8 / 9))$ groups compared to the non-atopic no rhinitis $(55.6 \%(10 / 18))$ group and rhinitis atopic group $(70.0 \%$ (21/30)). Among the participants who developed asthma, late onset asthma was most common in the non-atopic no rhinitis $(45.5 \%(15 / 33))$ and atopic no-rhinitis (55\% (11/20)) groups as compared with the nonatopic rhinitis $(36.7 \%(11 / 30))$ and atopic rhinitis $(11.8 \%$ (4/34)) groups.

\section{Discussion}

Using a non-selected longitudinal birth cohort, we examined the relationship between childhood rhinitis and subsequent development of asthma. As expected from individuals with the "atopic march", we found that atopic non-asthmatic children at age 6 were at risk for developing subsequent asthma, with or without of the presence of rhinitis. However, among non-asthmatic children at age 6 , active non-atopic rhinitis was also associated with a significantly increased risk for diagnosis of asthma through age 32 . This was true even after adjustment for known covariates such as sex, ethnicity, parental factors, smoke exposure, and colds. Further, the relationship between non-atopic rhinitis and asthma was independent of serum IgE.

The relationship between non-allergic rhinitis and asthma has been previously described but has not been assessed from childhood into adulthood. One cross-sectional population based study in young adults(37) showed that the risk of asthma among patients with rhinitis was not entirely dependent on atopy. Another cross-sectional study of young adults identified increased risk of asthma in patients with perennial, nonallergic rhinitis(38). A longitudinal study of adults followed for 8.8 years showed that non-allergic rhinitis conferred risk for development of asthma during that time period(39). Given the unique nature of our longitudinal birth cohort, this is the first report, to our knowledge, of early childhood nonatopic rhinitis conferring risk of asthma into adulthood.

Rhinitis is a heterogeneous disorder, and clinical features of rhinitis, including age of onset, relate to characteristics of asthma. For example, in the Isle of Wight cohort, a cluster 
analysis of early life factors revealed a relationship of early onset rhinitis (around age 6) with asthma that was moderately severe, early onset and atopic(40). Interestingly, in our cohort, active rhinitis at age 6 was indeed related to subsequent development of early-onset, persistent asthma, in both atopic and non-atopic rhinitis groups. While methodological differences in these papers preclude direct comparisons of the findings, a strong relationship between early rhinitis and asthma development, persistence, and severity emphasizes the potential importance of progressive expression of respiratory tract inflammation in the development of some phenotypes of persistent asthma.

Approximately half of our subjects with active rhinitis at age 6 were non-atopic, consistent with previous reports in children at age 5(41,42) and at age 4(42). In older children and adults, non-allergic rhinitis, defined as clinical presence of rhinitis without evidence of specific IgE antibodies against relevant antigens, has been attributed to environmental stimuli, such as in vasomotor rhinitis, cigarette smoke exposure, decongestant medication use, chronic rhinosinusitis, hormonal changes, viral illness, and anatomic abnormalities(19, $20,43)$. In this young pediatric population, however, chronic intranasal decongestant medication use and significant hormonal changes are likely to be rare. Cigarette smoke exposure at age 6 was identified in this population, but its presence did not show a relation with rhinitis, nor did it significantly interact with our outcome of asthma development. Entopy, a phenomenon of local allergen-specific IgE production, has also been proposed to cause non-allergic rhinitis but was not assessed in this cohort(44). However, viral rhinitis, vasomotor rhinitis, and chronic rhinosinusitis are the most likely causes of the rhinitis observed in our cohort at age 6 . When comparing clinical characteristics among the four groups, those with rhinitis had higher rates of reported sinusitis and frequent upper respiratory infection compared with the no rhinitis groups. While cross-sectional imaging and culture were not available to clarify the extent of each, both disorders could potentially confer significant non-atopic upper airway inflammation(45).

The goal of this work was to assess the development of asthma subsequent to the rhinitis determination at age 6 . Therefore, to minimize the likelihood that these children had preexisting asthma, this analysis excluded participants with a history of asthma or wheeze during the past year at age 6 and therefore, persistent and late wheezers(33) were excluded from this analysis. Measured lung function among the four rhinitis/atopy groups at age 6 was similar. Also, the early transient wheeze phenotype, described as wheeze during one or more lower respiratory illness during the first years of life but not past age 3(33), was not more frequent in children with non-atopic rhinitis than in those who had neither rhinitis nor atopy $(15,46)$. Taken together, these data suggest that the longitudinal association between non-atopic rhinitis by age 6 and subsequent asthma cannot be explained by abnormal early childhood lung function or subclinical asthma-like symptoms.

Establishing a definition of non-atopic rhinitis is challenging because of the potentially limitless number of antigens to which an individual may become exposed and sensitized.

However, skin prick testing for many dozens of aeroallergens is not generally appropriate in an epidemiological research setting, particularly with pediatric participants. The use of a representative panel of locally relevant aeroallergens to determine atopy has been successfully utilized to differentiate allergic from non-allergic disease(21). Further, using a 
limited allergen panel is an established method to define atopy in multiple longitudinal cohorts $(25,29,39)$. The panel utilized in the TCRS cohort was at the time(47), and remains, clinically relevant to patients in this geographic region(48).

To further characterize each group's clinical phenotype, we examined the frequency of atopy biomarkers and other allergic diseases present in these participants at age 6. Serum IgE level, a biomarker of atopy, was lower in both non-atopic groups at age 6 compared with the atopic groups. The presence of blood eosinophilia and diagnosis of eczema were also more frequent in the atopic groups. Thus, while the atopic groups were defined by skin testing results, characteristics of the participants in the atopic groups are consistent with conventional expectations of the clinical phenotype of allergic disease. Further, those with non-atopic rhinitis were not more likely to become atopic through age 26 than those nonatopics without rhinitis. These results suggest that development of atopy is not required for the development of asthma.

Because of the reported presence of disorders related to atopy in the non-atopic groups, we further assessed the risk of asthma development in a model adjusted by serum total IgE. Serum IgE levels, elevated in many atopic diseases, are often used as a surrogate marker of likelihood for atopic disease. Total IgE level is neither sensitive nor specific enough to confirm or rule out allergic disease, with the exception of very low or very high levels(49, 50). However, the relationship of an elevated serum IgE level in the absence of specific IgE to asthma was described in the Tucson Epidemiologic Study of Airways Obstructive Disease(51), a cohort of over 2600 non-Hispanic white subjects in Tucson who underwent phenotypic characterization and were followed longitudinally. In this study, serum IgE more accurately predicted asthma than skin prick test results. Despite this strong relationship between IgE level and asthma, in the TCRS cohort as presented, adjustment for serum IgE did not impact the relationship seen in the longitudinal models of asthma risk, suggesting that the relationship between rhinitis and asthma is independent of IgE. Additional analyses, not presented, related to eczema and eosinophil counts showed similar results. However, diagnosis of eczema and eosinophil counts were highly collinear with serum IgE, so these were not included in the final model.

A plausible connection between non-atopic rhinitis and subsequent asthma could be a common susceptibility to respiratory viral infection as has been reported for asthma(52). The most frequent cause of acute rhinitis is rhinovirus infection(53), and most asthma exacerbations in children and adults also have been found to be associated with rhinovirus infection(54). Strong evidence has accumulated suggesting that asthma patients have diminished interferon type I and type III responses to rhinoviruses $(55,56)$, and these alterations may be in part explained by genetic variants in innate immune genes such as CDHR3, which plays a critical role in responses to rhinovirus type C(57). Further, evidence supports a strong interaction between rhinovirus infection and the host's pre-existing immune milieu(58). For example, rhinovirus is expected to induce type 1 inflammation, characterized by interferons and growth factors, upon host infection. RSV can also induce a type 2 cytokine signature from epithelial cells, and innate lymphoid cells, which is pronounced in those with asthma(59) and is thought to be related to presence of $\operatorname{IgE}(60)$. Whether young children with non-atopic rhinitis may also have alterations of immune 
responses to viruses is currently unknown, but it is tempting to speculate that in some children, such alterations could first be expressed as upper airway symptoms and subsequently as asthma.

The strengths of our study include the use of a large, well-characterized birth cohort that has longitudinal data on health outcomes and characteristics, particularly regarding asthma and atopic disease, from birth through approximately age 32 . This study does have limitations, however. Some cohort participants were excluded from this analysis due to lack of data regarding the primary outcome (asthma) or lack of skin prick testing. The tables comparing characteristics of the missing and included individuals are presented in a supplemental figure. One additional weakness is the challenge defining absence of atopy, thereby proving a negative. It is not clear whether extending the aeroallergen testing panel at age 6 would have significantly changed the outcome of the groups as defined. Our analyses of risk of developing atopy subsequent to age 6 showed a similar rate of development of atopy over time, to larger panels, between the non-atopic groups which does not account for the asthma risk. Finally, temporally related factors that develop and compound over two decades of life such as smoke exposure and obesity, which may contribute to asthma risk and diagnosis, are not accounted for in these analyses but should be examined in future studies able to clarify these and other risk factors for asthma phenotypes.

In summary, our findings suggest that the connection between early life rhinitis and subsequent asthma is not fully explained by atopy, and that the presence of rhinitis confers significant risk for asthma independent of atopy. This novel pathway to the development of asthma warrants further study.

\section{Supplementary Material}

Refer to Web version on PubMed Central for supplementary material.

\section{Acknowledgements:}

The authors gratefully acknowledge the contributions of Lynn Taussig who started the Tucson Children's Respiratory Study in 1980. They thank Bruce Saul for data management and the study nurses, Marilyn Lindell, Lydia de la Ossa, and Nicole Pargas, for data collection and participant follow-up. They thank Lily Kim for assistance with manuscript data.

Funding sources: This work was funded by NIH grant HL 56177

\section{Abbreviations:}

HR

TCRS

URI

VmaxFRC
Hazard Ratio

Tucson Children's Respiratory Study

Upper respiratory infection

maximal forced expiratory flow at functional residual capacity 


\section{References}

1. Spergel JM. Epidemiology of atopic dermatitis and atopic march in children. Immunol Allergy Clin North Am. 2010;30(3):269-80. [PubMed: 20670812]

2. Spergel JM. From atopic dermatitis to asthma: the atopic march. Ann Allergy Asthma Immunol. 2010;105(2):99-106; quiz 7-9, 17. [PubMed: 20674819]

3. Rochat MK, Illi S, Ege MJ, Lau S, Keil T, Wahn U, et al. Allergic rhinitis as a predictor for wheezing onset in school-aged children. J Allergy Clin Immunol. 2010;126(6):1170-5.e2. [PubMed: 21051078]

4. Grabenhenrich LB, Gough H, Reich A, Eckers N, Zepp F, Nitsche O, et al. Early-life determinants of asthma from birth to age 20 years: a German birth cohort study. J Allergy Clin Immunol. 2014;133(4):979-88. [PubMed: 24461583]

5. Sherrill DL, Guerra S, Minervini MC, Wright AL, Martinez FD. The relation of rhinitis to recurrent cough and wheezing: a longitudinal study. Respir Med. 2005;99(11):1377-85. [PubMed: 15896950]

6. Burgess JA, Walters EH, Byrnes GB, Matheson MC, Jenkins MA, Wharton CL, et al. Childhood allergic rhinitis predicts asthma incidence and persistence to middle age: a longitudinal study. J Allergy Clin Immunol. 2007;120(4):863-9. [PubMed: 17825896]

7. Deliu M, Belgrave D, Simpson A, Murray CS, Kerry G, Custovic A. Impact of rhinitis on asthma severity in school-age children. Allergy. 2014;69(11):1515-21. [PubMed: 24958195]

8. Sly PD, Boner AL, Björksten B, Bush A, Custovic A, Eigenmann PA, et al. Early identification of atopy in the prediction of persistent asthma in children. Lancet. 2008;372(9643):1100-6. [PubMed: 18805338]

9. Pinart M, Benet M, Annesi-Maesano I, von Berg A, Berdel D, Carlsen KCL, et al. Comorbidity of eczema, rhinitis, and asthma in IgE-sensitised and non-IgE-sensitised children in MeDALL: A population-based cohort study. The Lancet Respiratory Medicine. 2014;2(2):131-40. [PubMed: 24503268]

10. Borish L The immunology of asthma: Asthma phenotypes and their implications for personalized treatment. Ann Allergy Asthma Immunol. 2016;117(2):108-14. [PubMed: 27499537]

11. Jones AC, Troy NM, White E, Hollams EM, Gout AM, Ling KM, et al. Persistent activation of interlinked type 2 airway epithelial gene networks in sputum-derived cells from aeroallergensensitized symptomatic asthmatics. Sci Rep. 2018;8(1):1511. [PubMed: 29367592]

12. Voraphani N, Stern DA, Wright AL, Guerra S, Morgan WJ, Martinez FD. Risk of current asthma among adult smokers with respiratory syncytial virus illnesses in early life. Am J Respir Crit Care Med. 2014;190(4):392-8. [PubMed: 24927374]

13. Jackson DJ, Gangnon RE, Evans MD, Roberg KA, Anderson EL, Pappas TE, et al. Wheezing rhinovirus illnesses in early life predict asthma development in high-risk children. Am J Respir Crit Care Med. 2008;178(7):667-72. [PubMed: 18565953]

14. Kusel MM, de Klerk NH, Kebadze T, Vohma V, Holt PG, Johnston SL, et al. Early-life respiratory viral infections, atopic sensitization, and risk of subsequent development of persistent asthma. $\mathrm{J}$ Allergy Clin Immunol. 2007;119(5):1105-10. [PubMed: 17353039]

15. Stern DA, Morgan WJ, Halonen M, Wright AL, Martinez FD. Wheezing and bronchial hyperresponsiveness in early childhood as predictors of newly diagnosed asthma in early adulthood: a longitudinal birth-cohort study. Lancet. 2008;372(9643):1058-64. [PubMed: 18805334]

16. Bacharier LB, Cohen R, Schweiger T, Yin-Declue H, Christie C, Zheng J, et al. Determinants of asthma after severe respiratory syncytial virus bronchiolitis. J Allergy Clin Immunol. 2012;130(1): 91-100.e3. [PubMed: 22444510]

17. Stein RT, Sherrill D, Morgan WJ, Holberg CJ, Halonen M, Taussig LM, et al. Respiratory syncytial virus in early life and risk of wheeze and allergy by age 13 years. Lancet. 1999;354(9178):541-5. [PubMed: 10470697]

18. Jackson DJ, Evans MD, Gangnon RE, Tisler CJ, Pappas TE, Lee WM, et al. Evidence for a causal relationship between allergic sensitization and rhinovirus wheezing in early life. Am J Respir Crit Care Med. 2012;185(3):281-5. [PubMed: 21960534] 
19. Peters AT, Spector S, Hsu J, Hamilos DL, Baroody FM, Chandra RK, et al. Diagnosis and management of rhinosinusitis: a practice parameter update. Ann Allergy Asthma Immunol. 2014;113(4):347-85. [PubMed: 25256029]

20. Roberts G, Xatzipsalti M, Borrego LM, Custovic A, Halken S, Hellings PW, et al. Paediatric rhinitis: Position paper of the European Academy of Allergy and Clinical Immunology. Allergy: European Journal of Allergy and Clinical Immunology. 2013;68(9):1102-16. [PubMed: 23952296]

21. Chawes BL, Kreiner-Moller E, Bisgaard H. Objective assessments of allergic and nonallergic rhinitis in young children. Allergy. 2009;64(10):1547-53. [PubMed: 19663868]

22. Erwin EA, Faust RA, Platts-Mills TA, Borish L. Epidemiological analysis of chronic rhinitis in pediatric patients. Am J Rhinol Allergy. 2011;25(5):327-32. [PubMed: 22186247]

23. Westman M, Stjarne P, Asarnoj A, Kull I, van Hage M, Wickman M, et al. Natural course and comorbidities of allergic and nonallergic rhinitis in children. J Allergy Clin Immunol. 2012;129(2): 403-8. [PubMed: 22056609]

24. Kurukulaaratchy RJ, Karmaus W, Raza A, Matthews S, Roberts G, Arshad SH. The influence of gender and atopy on the natural history of rhinitis in the first 18 years of life. Clin Exp Allergy. 2011;41(6):851-9. [PubMed: 21561494]

25. Chawes BL, Bonnelykke K, Kreiner-Moller E, Bisgaard H. Children with allergic and nonallergic rhinitis have a similar risk of asthma. J Allergy Clin Immunol. 2010;126(3):567-73.e1-8. [PubMed: 20816191]

26. Molgaard E, Thomsen SF, Lund T, Pedersen L, Nolte H, Backer V. Differences between allergic and nonallergic rhinitis in a large sample of adolescents and adults. Allergy. 2007;62(9):1033-7. [PubMed: 17578499]

27. Guerra S, Sherrill DL, Martinez FD, Barbee RA. Rhinitis as an independent risk factor for adultonset asthma. J Allergy Clin Immunol. 2002;109(3):419-25. [PubMed: 11897985]

28. Rolla G, Guida G, Heffler E, Badiu I, Bommarito L, De Stefani A, et al. Diagnostic classification of persistent rhinitis and its relationship to exhaled nitric oxide and asthma: a clinical study of a consecutive series of patients. Chest. 2007;131(5):1345-52. [PubMed: 17317733]

29. Taussig LM, Wright AL, Holberg CJ, Halonen M, Morgan WJ, Martinez FD. Tucson Children's Respiratory Study: 1980 to present. J Allergy Clin Immunol. 2003;111(4):661-75; quiz 76. [PubMed: 12704342]

30. Taussig LM, Wright AL, Morgan WJ, Harrison HR, Ray CG. The Tucson Children's Respiratory Study. I. Design and implementation of a prospective study of acute and chronic respiratory illness in children. American journal of epidemiology. 1989;129(6):1219-31. [PubMed: 2729258]

31. Martinez FD, Stern DA, Wright AL, Taussig LM, Halonen M. Association of non-wheezing lower respiratory tract illnesses in early life with persistently diminished serum IgE levels. Group Health Medical Associates. Thorax. 1995;50(10):1067-72. [PubMed: 7491555]

32. Karakoc F, Remes ST, Martinez FD, Wright AL. The association between persistent eosinophilia and asthma in childhood is independent of atopic status. Clin Exp Allergy. 2002;32(1):51-6. [PubMed: 12002737]

33. Martinez FD, Wright AL, Taussig LM, Holberg CJ, Halonen M, Morgan WJ. Asthma and wheezing in the first six years of life. The Group Health Medical Associates. N Engl J Med. 1995;332(3):133-8. [PubMed: 7800004]

34. Lombardi E, Morgan WJ, Wright AL, Stein RT, Holberg CJ, Martinez FD. Cold air challenge at age 6 and subsequent incidence of asthma. A longitudinal study. Am J Respir Crit Care Med. 1997;156(6):1863-9. [PubMed: 9412567]

35. Stern DA, Lohman IC, Wright AL, Taussig LM, Martinez FD, Halonen M. Dynamic changes in sensitization to specific aeroallergens in children raised in a desert environment. Clin Exp Allergy. 2004;34(10):1563-669. [PubMed: 15479271]

36. Gerhart KD, Stern DA, Guerra S, Morgan WJ, Martinez FD, Wright AL. Protective effect of breastfeeding on recurrent cough in adulthood. Thorax. 2018;73(9):833-9. [PubMed: 29786547]

37. Leynaert B, Neukirch C, Kony S, Guénégou A, Bousquet J, Aubier M, et al. Association between asthma and rhinitis according to atopic sensitization in a population-based study. J Allergy Clin Immunol. 2004;113(1):86-93. [PubMed: 14713912] 
38. Leynaert B, Bousquet J, Neukirch C, Liard R, Neukirch F. Perennial rhinitis: An independent risk factor for asthma in nonatopic subjects: results from the European Community Respiratory Health Survey. J Allergy Clin Immunol. 1999;104(2 Pt 1):301-4. [PubMed: 10452748]

39. Shaaban R, Zureik M, Soussan D, Neukirch C, Heinrich J, Sunyer J, et al. Rhinitis and onset of asthma: a longitudinal population-based study. Lancet. 2008;372(9643):1049-57. [PubMed: 18805333]

40. Kurukulaaratchy RJ, Zhang H, Patil V, Raza A, Karmaus W, Ewart S, et al. Identifying the heterogeneity of young adult rhinitis through cluster analysis in the Isle of Wight birth cohort. J Allergy Clin Immunol. 2015;135(1):143-50. [PubMed: 25085342]

41. Marinho S, Simpson A, Lowe L, Kissen P, Murray C, Custovic A. Rhinoconjunctivitis in 5-yearold children: a population-based birth cohort study. Allergy. 2007;62(4):385-93. [PubMed: 17362249]

42. Arshad SH, Tariq SM, Matthews S, Hakim E. Sensitization to common allergens and its association with allergic disorders at age 4 years: a whole population birth cohort study. Pediatrics. 2001;108(2):E33. [PubMed: 11483843]

43. Wallace DV, Dykewicz MS, Bernstein DI, Blessing-Moore J, Cox L, Khan DA, et al. The diagnosis and management of rhinitis: an updated practice parameter. J Allergy Clin Immunol. 2008;122(2 Suppl):S1-84. [PubMed: 18662584]

44. Baraniuk JN. Pathogenic mechanisms of idiopathic nonallergic rhinitis. World Allergy Organ J. 2009;2(6):106-14. [PubMed: 24229057]

45. Stevens WW, Lee RJ, Schleimer RP, Cohen NA. Chronic rhinosinusitis pathogenesis. J Allergy Clin Immunol. 2015;136(6):1442-53. [PubMed: 26654193]

46. Morgan WJ, Stern DA, Sherrill DL, Guerra S, Holberg CJ, Guilbert TW, et al. Outcome of asthma and wheezing in the first 6 years of life: follow-up through adolescence. Am J Respir Crit Care Med. 2005;172(10):1253-8. [PubMed: 16109980]

47. Robertson G, Lebowitz MD. Analysis of relationships between symptoms and environmental factors over time. Environ Res. 1984;33(1):130-43. [PubMed: 6692807]

48. Buckley RD, Carr TF. Association of aeroallergen sensitization and atopic disease in the Sonoran Desert. Allergy Asthma Proc. 2017;38(5):370-5. [PubMed: 28814357]

49. Sinclair D, Peters SA. The predictive value of total serum IgE for a positive allergen specific IgE result. J Clin Pathol. 2004;57(9):956-9. [PubMed: 15333657]

50. Barbee RA, Halonen M, Lebowitz M, Burrows B. Distribution of IgE in a community population sample: correlations with age, sex, and allergen skin test reactivity. J Allergy Clin Immunol. 1981;68(2):106-11. [PubMed: 7251998]

51. Burrows B, Martinez FD, Halonen M, Barbee RA, Cline MG. Association of asthma with serum IgE levels and skin-test reactivity to allergens. N Engl J Med. 1989;320(5):271-7. [PubMed: 2911321]

52. Bonnelykke K, Vissing NH, Sevelsted A, Johnston SL, Bisgaard H. Association between respiratory infections in early life and later asthma is independent of virus type. J Allergy Clin Immunol. 2015;136(1):81-6.e4. [PubMed: 25910716]

53. Olenec JP, Kim WK, Lee WM, Vang F, Pappas TE, Salazar LE, et al. Weekly monitoring of children with asthma for infections and illness during common cold seasons. J Allergy Clin Immunol. 2010;125(5):1001-6.e1. [PubMed: 20392488]

54. Jackson DJ, Johnston SL. The role of viruses in acute exacerbations of asthma. J Allergy Clin Immunol. 2010;125(6):1178-87; quiz 88-9. [PubMed: 20513517]

55. Edwards MR, Johnston SL. Deficient interferon in virus-induced asthma exacerbations. Clin Exp Allergy. 2008;38(9):1416-8. [PubMed: 18644024]

56. Bosco A, Ehteshami S, Panyala S, Martinez FD. Interferon regulatory factor 7 is a major hub connecting interferon-mediated responses in virus-induced asthma exacerbations in vivo. J Allergy Clin Immunol. 2012;129(1):88-94. [PubMed: 22112518]

57. Bochkov YA, Watters K, Ashraf S, Griggs TF, Devries MK, Jackson DJ, et al. Cadherin-related family member 3 , a childhood asthma susceptibility gene product, mediates rhinovirus $\mathrm{C}$ binding and replication. Proc Natl Acad Sci U S A. 2015;112(17):5485-90. [PubMed: 25848009] 
58. Steinke JW, Borish L. Immune Responses in Rhinovirus-Induced Asthma Exacerbations. Curr Allergy Asthma Rep. 2016;16(11):78. [PubMed: 27796793]

59. Jackson DJ, Makrinioti H, Rana BM, Shamji BW, Trujillo-Torralbo MB, Footitt J, et al. IL-33dependent type 2 inflammation during rhinovirus-induced asthma exacerbations in vivo. Am J Respir Crit Care Med. 2014;190(12):1373-82. [PubMed: 25350863]

60. Teach SJ, Gill MA, Togias A, Sorkness CA, Arbes SJ, Jr., Calatroni A, et al. Preseasonal treatment with either omalizumab or an inhaled corticosteroid boost to prevent fall asthma exacerbations. J Allergy Clin Immunol. 2015;136(6):1476-85. [PubMed: 26518090] 


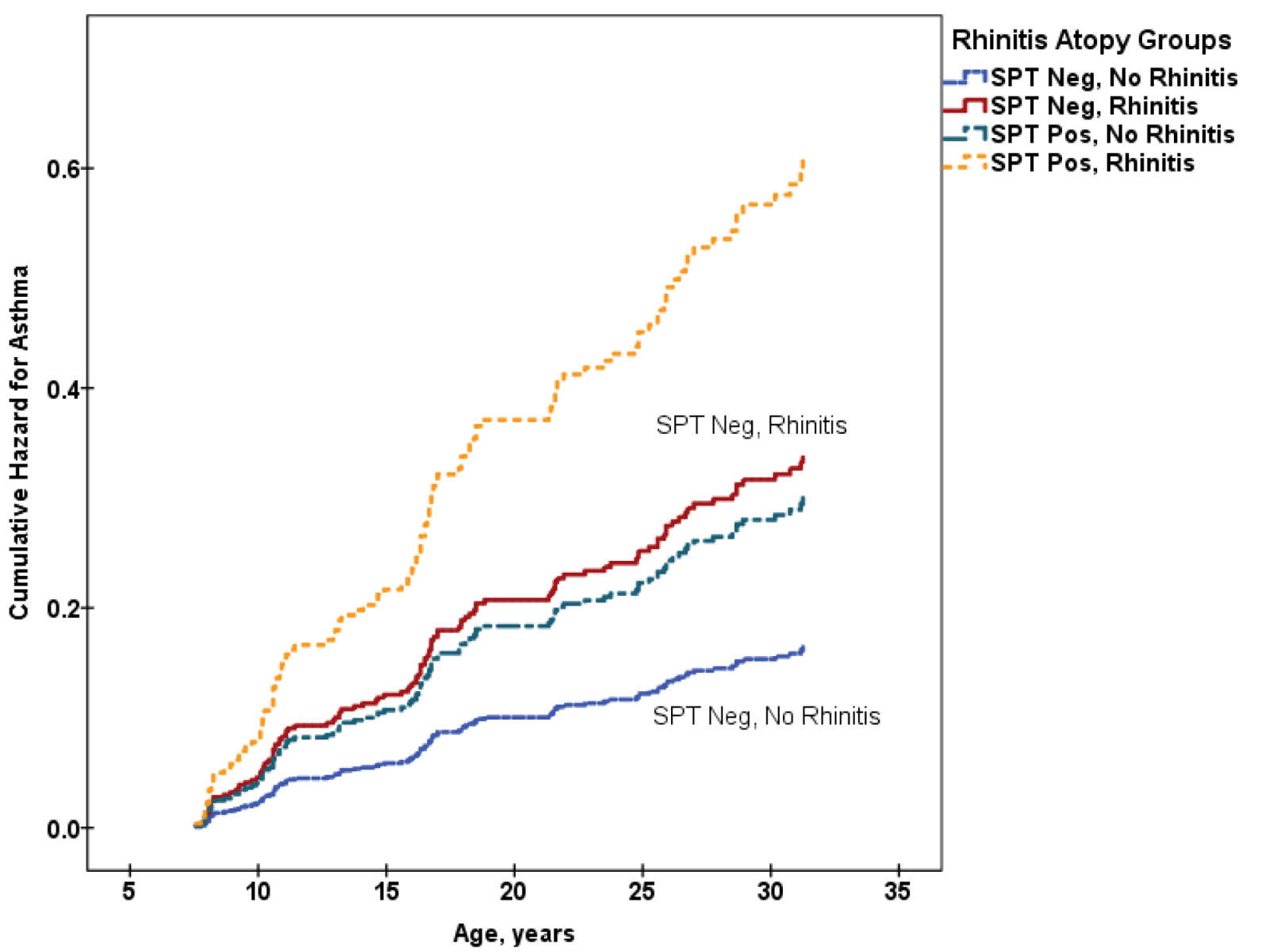

Figure I.

Cox hazards for asthma by rhinitis and atopic group status 


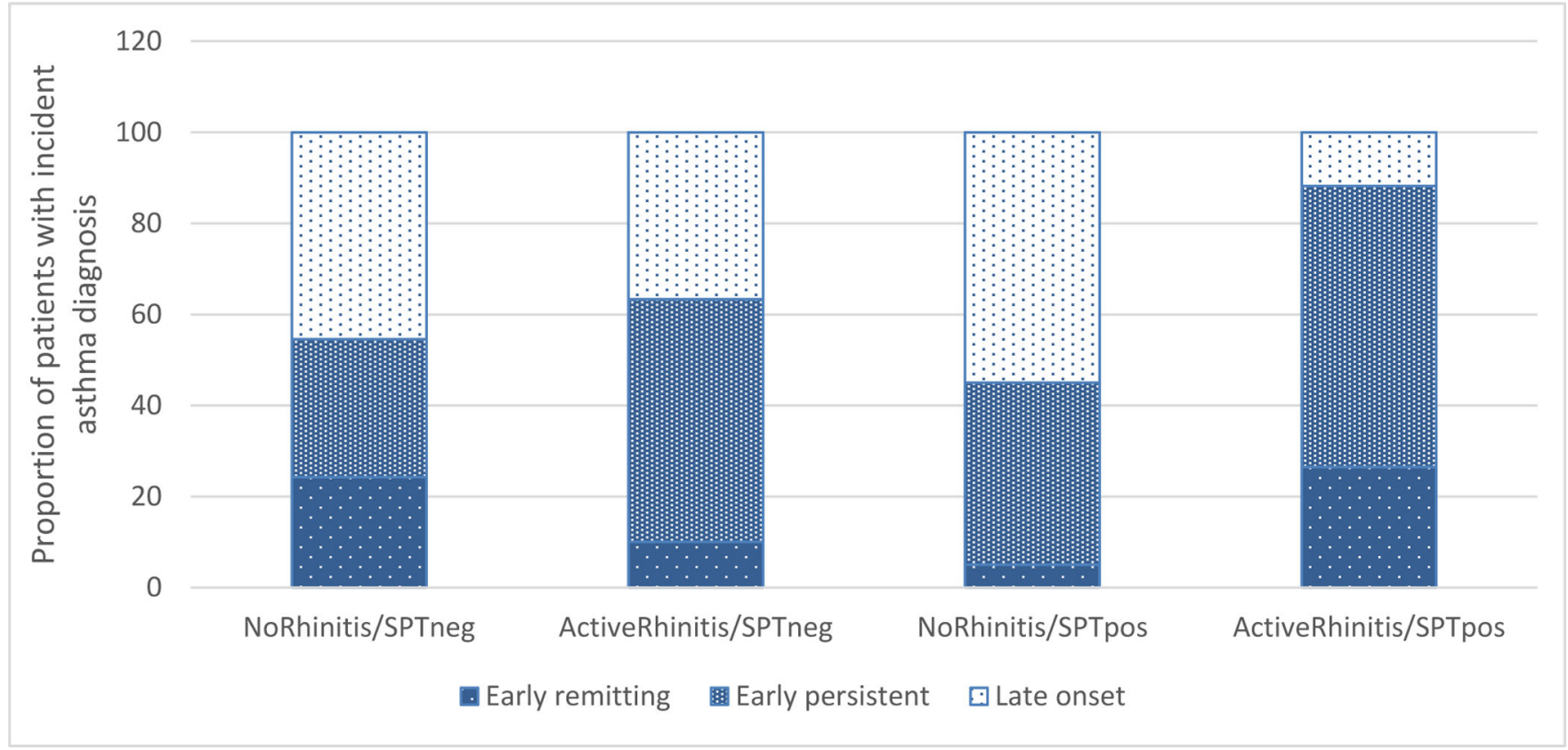

Figure 2.

Proportion of patients with early onset remitting, early onset persistent, and late onset asthma, by rhinitis and atopy group. 


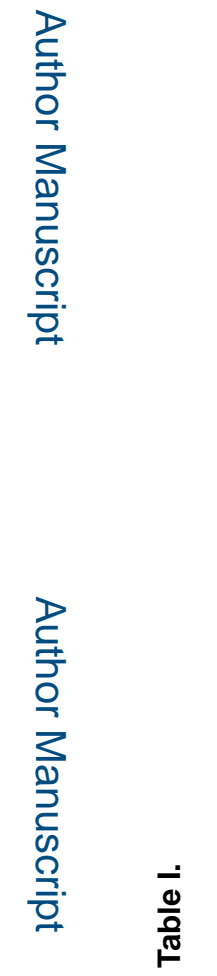

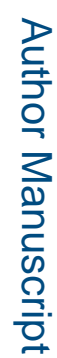

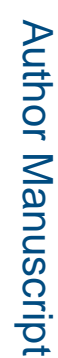

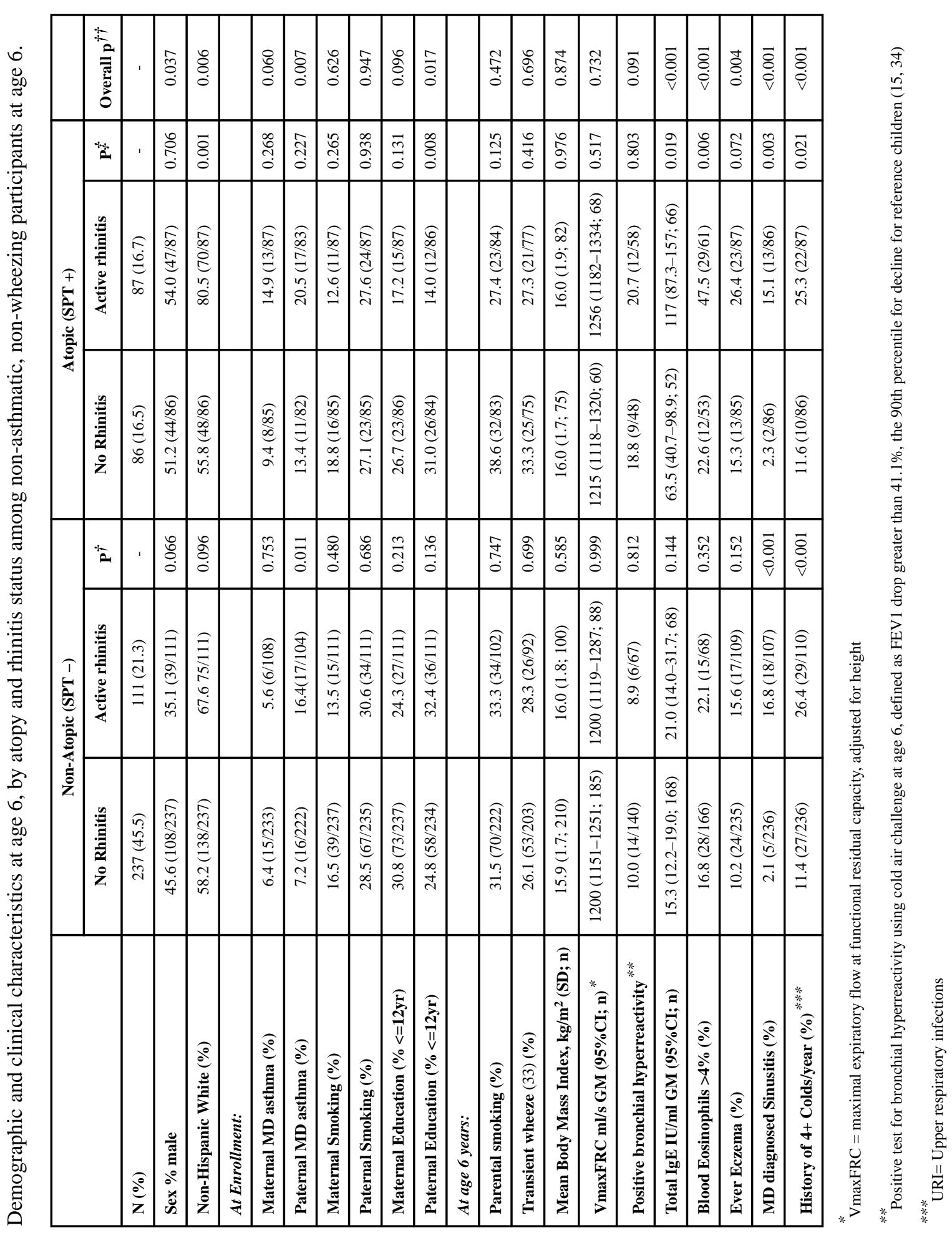

Clin Exp Allergy. Author manuscript; available in PMC 2020 January 01. 


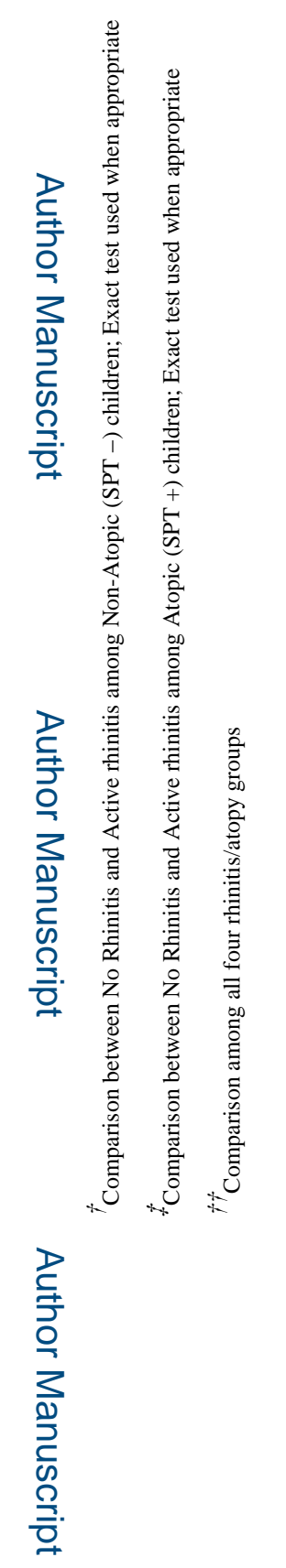

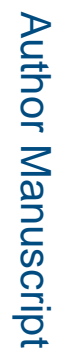

Clin Exp Allergy. Author manuscript; available in PMC 2020 January 01. 


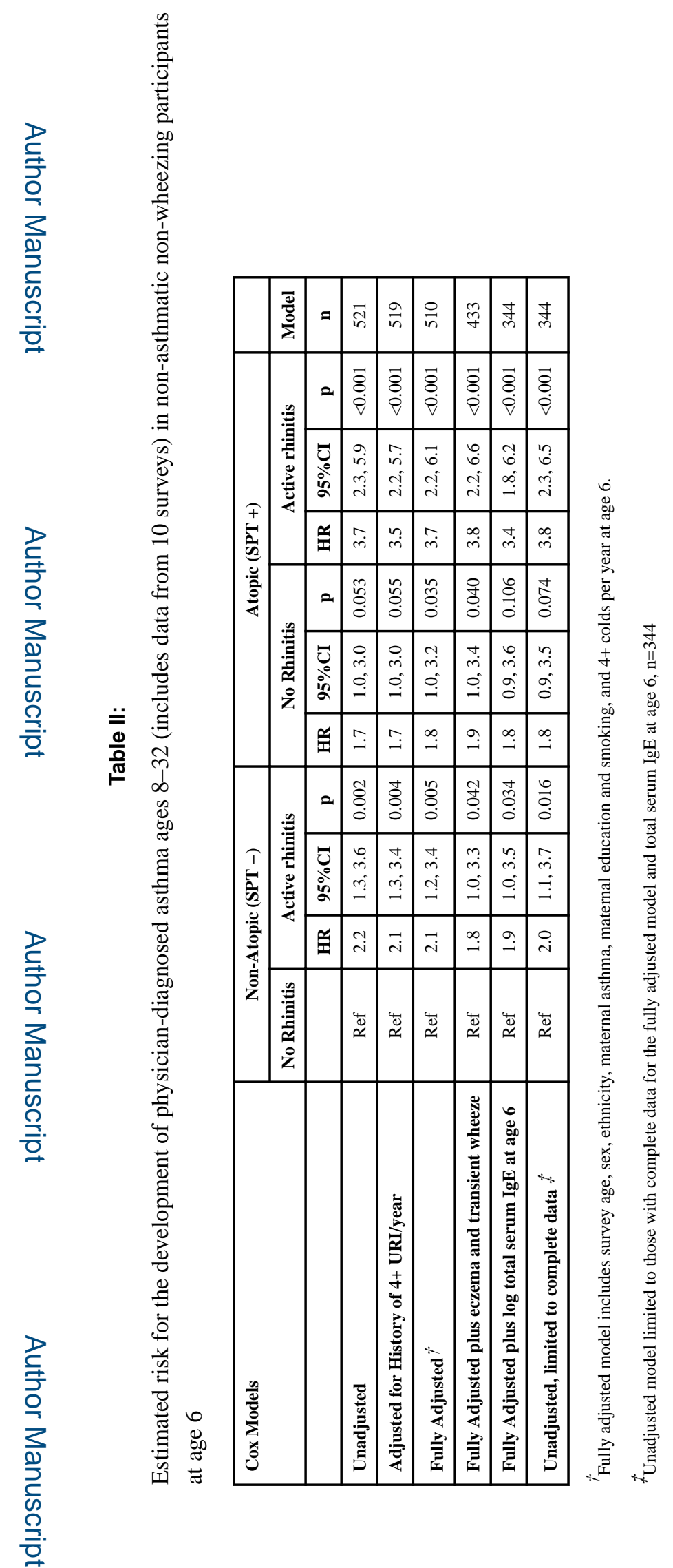

Clin Exp Allergy. Author manuscript; available in PMC 2020 January 01. 
Table III.

Positive skin prick test results through age 26 among participants who were non-atopic at age 6 .

\begin{tabular}{|l|l|c|c|c|c|c|c|c|c|}
\hline & & \multicolumn{6}{|c|}{ Skin Prick Test Results } \\
\hline & & \multicolumn{2}{|c|}{$\mathbf{1 1}$} & \multicolumn{2}{|c|}{$\mathbf{1 6}$} & \multicolumn{2}{|c|}{$\mathbf{2 2}$} & \multicolumn{2}{|c|}{$\mathbf{2 6}$} \\
\hline & & $\mathbf{n}^{*}$ & $\mathbf{\%}$ positive & $\mathbf{n}$ & \% positive & $\mathbf{n}$ & \% positive & n & \% positive \\
\hline \multirow{2}{*}{ Non-Atopic (SPT -) at age 6 } & No Rhinitis & 206 & 27.7 & 153 & 52.3 & 140 & 55.0 & 121 & 56.2 \\
\cline { 2 - 13 } & Active rhinitis & 93 & 34.4 & 69 & 52.2 & 64 & 50.0 & 52 & 55.8 \\
\hline $\mathbf{p}=$ & & & 0.238 & & 0.987 & & 0.506 & & 0.958 \\
\hline
\end{tabular}

At each age, the $\mathrm{n}$ value reflects the number of participants who underwent skin prick testing at that visit; changes reflect study attrition. 